OPEN ACCESS

Edited by:

Le Jian,

Government of Western Australia Department of Health, Australia

Reviewed by: Jacopo Lenzi,

University of Bologna, Italy

Gabriele Messina,

University of Siena, Italy

*Correspondence:

Mario Cesare Nurchis mariocesare.nurchis@unicatt.it

Specialty section: This article was submitted to

Public Health Policy,

a section of the journal

Frontiers in Public Health

Received: 26 April 2021 Accepted: 08 September 2021

Published: 05 October 2021

Citation:

Gianino MM, Nurchis MC, Politano G,

Rousset $S$ and Damiani G (2021)

Evaluation of the Strategies to Control

COVID-19 Pandemic in Four

European Countries.

Front. Public Health 9:700811.

doi: 10.3389/fpubh.2021.700811

\section{Evaluation of the Strategies to Control COVID-19 Pandemic in Four European Countries}

\author{
Maria Michela Gianino ${ }^{1}$, Mario Cesare Nurchis ${ }^{2 *}$, Gianfranco Politano ${ }^{3}$, Stefano Rousset ${ }^{1}$ \\ and Gianfranco Damiani ${ }^{2,4}$ \\ ${ }^{1}$ Department of Public Health and Paediatrics, Università di Torino, Torino, Italy, ${ }^{2}$ Department of Woman and Child Health \\ and Public Health, Fondazione Policlinico Universitario A. Gemelli IRCCS, Roma, Italy, ${ }^{3}$ Department of Control and Computer \\ Engineering, Politecnico di Torino, Torino, Italy, ${ }^{4}$ Department of Health Sciences and Public Health, Section of Hygiene, \\ Universito Cattolica del Sacro Cuore, Roma, Italy
}

On March 11, 2020, the World Health Organization (WHO) has officially declared the novel coronavirus outbreak a pandemic. The national governments deployed a series of severe control measures and a set of public health policies in order to stop the spread of COVID-19 pandemic. The aim of this study is to investigate the correlation between specific interventions and incident cases during the second wave in multiple and specific countries. The observational study was based on data from the Oxford COVID-19 Government Response Tracker (OxCGRT) source retrieved from October 1st, 2020 to January 10, 2021. Thirteen specific indicators related to measures adopted were considered. Four European countries were taken into account: Italy, German, Spain and UK. A vector autoregression (VAR) model and the Granger Causality test were performed to allow for an assessment of any possible effect induced by each control measure against the overall pandemic growth. Wald test was conducted to compute $p$-values. No correlation between the applied measures and incident cases in the four countries was shown by the Granger causality test. Only closings of workplaces (C2) and limits on private gatherings showed (C4) a significant correlation with incident cases in UK and restrictions on internal movement between cities/regions in Germany. The Granger causality also tested that C2 and C4 forecasted the decrease of incident cases after a time lag of 6-30 days in UK and Germany, respectively. Policy makers must analyze the context in which policies are set because of effectiveness of interventions can be influenced by local context and, especially, by socio-economic and demographic characteristics, and make a proper communication to support the resilience of the population capable of guaranteeing adherence to the interventions implemented.

Keywords: stringency index, indicators, containment measures, public health measure, COVID-19

\section{INTRODUCTION}

On March 11, 2020, the World Health Organization (WHO) has officially declared the novel coronavirus outbreak a pandemic (1).

In most countries that have declared health emergencies to counteract the spread of coronavirus disease 2019 (COVID-19), measures have been adopted for the containment and management of 
the epidemiological emergency from COVID-19. Among the containment measures, defined as an intervention applied to a community in order to lower intermixing of unreported infectious individuals with susceptibles as well as the spread of the virus $(2,3)$, there are public health measures and government measures.

The national governments deployed a series of severe control measures (e.g., orders to stay at home, restricting travel, closing non-essential businesses, closing schools and other gathering places) and a set of public health policies (e.g., prevention and protection measures as washing or disinfecting hands with the appropriate disinfectant gel, using gloves, wearing a mask) aimed to curb the transmission of COVID-19 pandemic $(4,5)$.

The adoption of these measures occurs simultaneously in some countries while in others at different times, their maintenance is often discontinuous, and the application is carried out with different intensity. In addition, the measures that were adopted and how quickly they were embraced varied substantially-both across countries, and often within countries $(4,5)$.

These heterogeneities together with the specific political and socio-demographical contexts make the comparisons of the effectiveness of international pandemic responses complex.

However, the Oxford COVID-19 Government Response Tracker (OxCGRT) is a tool that allows for international comparison. This project provides a total of 19 indicators, of which eight are related to closures and containment measures, four to economic measures and seven to health measures. For each of them a different ordinal value indicates the score and, data is collected and updated in real time and reported daily (6).

Previous studies have investigated the effect of interventions on COVID-19 infection rates. Nevertheless, these studies either used composite measures - which combine different indicators into a general index (4) -, or inferred effectiveness of specific interventions, including social distancing (7) and travel restriction $(8,9)$, from a pool of countries or focused on a single country $(10,11)$. These studies are typically related to the first wave of the pandemic.

The aim of this study is to investigate the correlation between specific interventions and incident cases during the second wave in multiple and specific countries.

\section{MATERIALS AND METHODS}

Thirteen specific indicators were analyzed: eight were related to closures and containment measures while five to health measures. All of them are related to measures imposed to limit the transmission of COVID-19. Data of the 13 indicators, from October 1st, 2020 to January 10, 2021, were downloaded from the OxCGRT database (12) on January 15, 2021. Daily incident data on confirmed cases were used and retrieved from the OxCGRT database.

The indicators considered in the present study are shown in Table 1, which illustrates the definition, source and unit of measure for each item. Four European countries were taken into account: Italy, German, Spain and UK.

The original 13 indicators were loaded as time series in an R (13) custom pipeline and analyzed in terms of variance. Given the presence of a seasonal (weekly) pattern in confirmed daily cases, we performed a trend extraction by removing this high frequency seasonal noise to enforce the estimation reliability.

To assess any possible effect induced by each control measure against the overall pandemic growth, we resorted to the $\mathrm{R}$ vars package (14), which aims at estimation, forecasting and causality analysis by resorting to Vector autoregression (VAR) modeling to capture the relationship between multiple quantities as they change over time. To enforce and quantify the robustness of the causality estimation, we modeled the inference problem taking advantage of the Granger Causality test, thus fitting a VAR model and testing the hypothesis that the increase of any predictor Granger causes a decrease in infection growth. The $p$-value so far computed comes from a Wald test.

More in details: data has been transformed in a timeseries (using function ts from \{stats\} package) with a weekly frequency (according to major weekly patterns present in data, i.e., recurrent reduction in numbers during week-end) then we applied a seasonal decomposition (stl function in $\{$ stats $\}$ package) to extract seasonal, trend and irregular components using a periodic loess interpolation.

Time lags have been automatically identified resorting to the VARselect function in $\{$ vars $\}$ package, which automatically increases the lag order up to 30 days. This limit has been chosen as a $25 \%$ percentage of the maximum time span of 4,5 months available in raw data. Resorting to the best fitting time lag identified by VARselect we then computed the estimated VAR by utilizing OLS per equation (VAR function in $\{$ vars $\}$ package) and eventually computing the test statistics for Granger and Instantaneous causality for that VAR (causality function in $\{$ vars $\}$ package).

\section{RESULTS}

All the indicators $\mathrm{C} 1, \mathrm{C} 2, \mathrm{C} 4, \mathrm{C} 7, \mathrm{C} 8, \mathrm{H} 3$, were analyzed. The other indicators (i.e., C3, C5, C6, H1, H2) were not analyzed since the four considered countries deployed these interventions over the entire time span without any different intensity.

Figure 1 shows the values' trend of indicators and the trend of incremental confirmed cases across the four countries.

The Granger causality test (Table 2) showed that there was no correlation between the applied interventions and incident cases. Only C2 and C4 showed a significant correlation with incident cases in UK and C7 in Germany. The Granger causality also tested that $\mathrm{C} 2$ and $\mathrm{C} 4$ forecasted the decrease of incident cases after a time lag of 6 days in UK and C7 after 30 days in Germany. Other analyzed indicators did not show any significant correlation, thus they have been not reported in significant results.

\section{DISCUSSION}

This study represents an interesting observational effort to evaluate the causality relationship of specific measures on incident cases. This approach is differentiated from previous studies that evaluated full down strategies $(5,15)$ or composite measures - which combine different indicators into a general 
TABLE 1 | Indicators, definitions, and coding*.

\begin{tabular}{llll}
\hline Indicators Definition Coding & C C
\end{tabular}

C1
Record closings of schools and universities

Record closings of workplaces

Record canceling public events

Record limits on private gatherings

Record closing of public transport

Record orders to "shelter-in-place" and otherwise confine to the home

Record restrictions on internal movement between cities/regions

Record restrictions on international travel Note: this records policy for foreign travelers, not citizens

Record presence of public info campaigns

Record government policy on who has access to testing Note: this records policies about testing for current infection (PCR tests) not testing for immunity (antibody test)

Record government policy on contact tracing after a positive diagnosis Note: we are looking for policies that would identify all people potentially exposed to Covid-19; voluntary Bluetooth apps are unlikely to achieve this

Record policies on the use of facial coverings outside the home

Record policies for vaccine delivery for different groups
0. no measures 1. recommend closing or all schools open with alterations resulting in significant differences compared to non-Covid-19 operations 2. require closing (only some levels or categories, e.g., just high school, or just public schools) 3. require closing all levels Blank - no data

0. no measures 1. recommend closing (or recommend work from home) 2. require closing (or work from home) for some sectors or categories of workers 3. require closing (or work from home) for all-but-essential workplaces (e.g., grocery stores, doctors) Blank - no data

0. no measures 1. recommend canceling 2. require canceling Blank - no data

0 . no restrictions 1. restrictions on very large gatherings (the limit is above 1,000 people) 2. restrictions on gatherings between 101-1,000 people 3 . restrictions on gatherings between 11-100 people 4. restrictions on gatherings of 10 people or less Blank - no data

0. no measures 1. recommend closing (or significantly reduce volume/route/means of transport available) 2. require closing (or prohibit most citizens from using it) Blank - no data

0. no measures 1. recommend not leaving house 2. require not leaving house with exceptions for daily exercise, grocery shopping, and 'essential' trips 3. require not leaving house with minimal exceptions (e.g., allowed to leave once a week, or only one person can leave at a time, etc.) Blank - no data

0. no measures 1. recommend not to travel between regions/cities 2 . internal movement restrictions in place Blank - no data

0 . no restrictions 1. screening arrivals 2. quarantine arrivals from some or all regions 3 . ban arrivals from some regions 4 . ban on all regions or total border closure Blank - no data

0. no Covid-19 public information campaign 1. public officials urging caution about Covid-19 2. coordinated public information campaign (e.g., across traditional and social media) Blank - no data

0 . no testing policy 1. only those who both (a) have symptoms AND (b) meet specific criteria (e.g., key workers, admitted to hospital, came into contact with a known case, returned from overseas) 2. testing of anyone showing Covid-19 symptoms 3. open public testing (e.g., "drive through" testing available to asymptomatic people) Blank - no data

0 . no contact tracing 1. limited contact tracing; not done for all cases 2. comprehensive contact tracing; done for all identified cases

0. No policy 1. Recommended 2. Required in some specified shared/public spaces outside the home with other people present, or some situations when social distancing not possible 3. Required in all shared/public spaces outside the home with other people present or all situations when social distancing not possible 4. Required outside the home at all times regardless of location or presence of other people

0 . No availability 1. Availability for ONE of following: key workers/clinically vulnerable groups/elderly groups 2. Availability for TWO of following: key workers/clinically vulnerable groups/elderly groups 3. Availability for ALL of following: key workers/clinically vulnerable groups/elderly groups 4 . Availability for all three plus partial additional availability (select broad groups/ages) 5. Universal availability

*Indicators, definitions and coding are reported as provided in Oxford COVID-19 Government Response Tracker (OxCGRT) raw data (12).

index (4). Both of these approaches inevitably are abstract away from the significant nuance and heterogeneity exhibited by health policies' and Governments' responses. In addition, this study is an alternative approach to predictive studies that explore scenarios making strong assumptions that may be difficult to validate (9). 


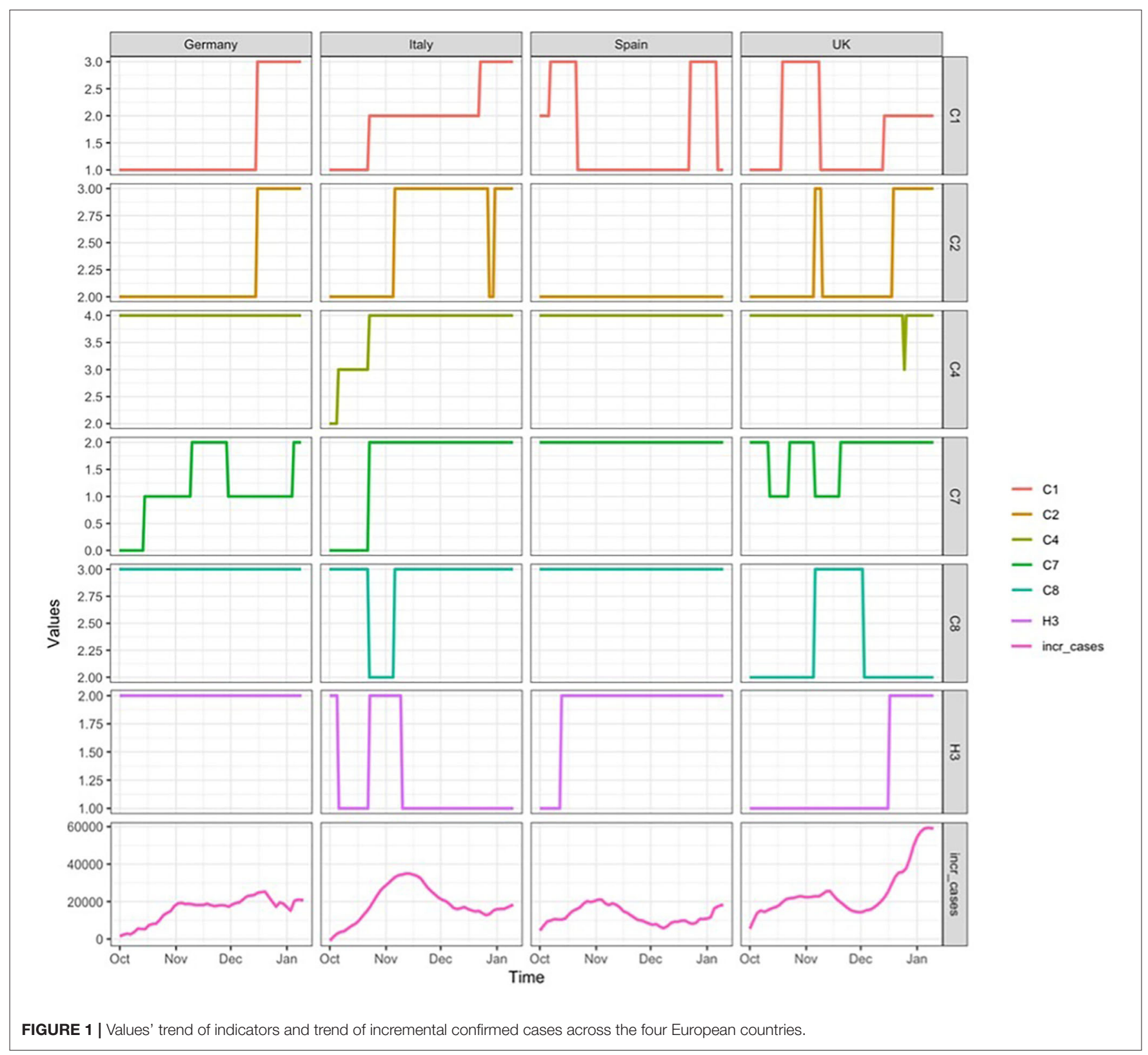

Our results pointed out that the most of specific interventions analyzed for Italy, German, Spain and UK are not correlated with incident cases of COVID-19. These results are in contrast to a previous study which showed that some interventions are effective to reducing transmission at the advent of the pandemic, highlighting that closing both schools and universities and limiting gatherings to 10 people produced a large effect while closing non-essential businesses produced a moderate effect (9). Anyhow, this study did not evaluate the effects across the countries.

Moreover, our results revealed that $\mathrm{C} 2$ e C4 have a Granger causality only in UK and C7 only in Germany.

The joint reading of our results leads to some suggestions.
First, like any policy intervention, the effect is likely to be highly contingent on local political and social contexts. A previous study (16) found that the effectiveness of many interventions depends on the local context and, in general, the effectiveness of social distancing measures and travel restrictions varies considerably across countries.

Second, the compliance with the measures may affect the spread of COVID-19. This suggestion is supported by evidence in the literature that identified demographic and socio-economic factors as variables able to influence the adherence with COVID19 guidelines. According to previous studies, adolescents and young adults belong to a group that is the least likely to follow measures aimed at curbing the spread of COVID-2019, especially 
TABLE 2 | Results of the granger causality test and AIC days for four European countries (from 01/10/2020 to 10/01/2021).

\begin{tabular}{|c|c|c|c|c|c|c|c|c|c|}
\hline \multirow[t]{2}{*}{ Ind. } & \multirow[t]{2}{*}{ Definition } & \multirow{2}{*}{$\begin{array}{l}\text { Germany } \\
P \text {-value }\end{array}$} & \multicolumn{3}{|c|}{ Italy } & \multirow{2}{*}{$\begin{array}{c}\text { Spain } \\
P \text {-value }\end{array}$} & \multicolumn{3}{|c|}{ UK } \\
\hline & & & AIC days & $P$-value & AIC days & & AIC days & $P$-value & AIC days \\
\hline C1 & Record closings of schools and universities & $\mathrm{N} / \mathrm{A}$ & 29 & 0,257 & 29 & 0,648 & 30 & 0,294 & 30 \\
\hline $\mathrm{C} 2$ & Record closings of workplaces & $\mathrm{N} / \mathrm{A}$ & 29 & 0,969 & 30 & N/A & 0 & $0,042^{*}$ & 6 \\
\hline $\mathrm{C} 4$ & Record limits on private gatherings & $\mathrm{N} / \mathrm{A}$ & 0 & $\mathrm{~N} / \mathrm{A}$ & 30 & N/A & 0 & $0,014^{*}$ & 6 \\
\hline $\mathrm{C} 7$ & $\begin{array}{l}\text { Record restrictions on internal movement } \\
\text { between cities/regions }\end{array}$ & $0,003^{\star}$ & 30 & $\mathrm{~N} / \mathrm{A}$ & 30 & N/A & 0 & 0,219 & 30 \\
\hline $\mathrm{C} 8$ & Record restrictions on international travel & $\mathrm{N} / \mathrm{A}$ & 0 & 0,719 & 30 & N/A & 0 & 0,779 & 30 \\
\hline H3 & $\begin{array}{l}\text { Record government policy on contact tracing } \\
\text { after a positive diagnosis }\end{array}$ & $\mathrm{N} / \mathrm{A}$ & 0 & 0,984 & 30 & N/A & 28 & 0,063 & 8 \\
\hline
\end{tabular}

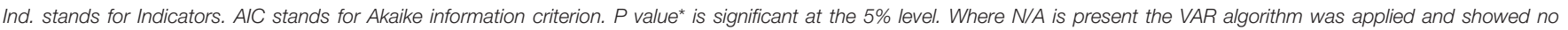
convergence, thus no results are available.

the recommended practices about hand-washing, self-isolation and social distancing (17-20).

A study in UK found that low compliance was strongly related to younger age, risk attitudes and high income, and that individuals living in overcrowded accommodation and neighborhoods with little space had lower and faster decreasing compliance (21). Another study in UK, justifying the Granger causality for $\mathrm{C} 4$ especially, tested that there was high compliance to social distancing and isolation guidelines reported across the study sample, and reported that lack of social conscience and lack of understanding a as likely causes of instances of nonadherence (22).

Additionally, the success of public health measures rests on the public's willingness to comply and the compliance with directives and recommended health behaviors is a longstanding and known problem (23). People routinely refuse to cease behavior that is bad for them and do not do what is good for them. This same pattern of behavior should be expected when it comes to COVID-19 restrictions being implemented. Just as people continue to smoke, to drink, to refuse to physical activity, to underestimate dietary risks, and even to reject required medication, so people will test the boundaries of government instructions, and many will simply refuse to comply.

Third, how and how well policies are enforced can affect the effectiveness of public health measures and government measures. To contain the COVID-19 pandemic, a critical decision is the extent to which policy makers rely either on voluntary or on enforced compliance. A survey conducted in Germany found that the effectiveness of voluntary compared with enforced measures to address the COVID-19 pandemic will differ across populations and suggests that enforcement might create less resistance in countries where trust in government is higher than in countries where trust in government is lower (10). In this way, an Italian study pointed out that, in Italy, the level of social and institutional trust is significantly low and Italians are known to live among relatives in large communities where close contact and deep personal interactions are the social glue. Consequently, due to the special familiar and relational structure and functioning of Italian society, the measures may be supported more under voluntary than under enforced implementation and the policy makers should have included risk communication measures able to educate and to encourage people to "don't meet anyone rather than merely stay at home" (24).

The results of this study and the subsequent preliminary conclusions must be considered in light of the study's weaknesses. The main limitations are those of the database used and are common to all administrative database studies. Firstly, there are problems related to the quality of the data which does not detect all significant nuance and heterogeneity of Governments' responses to COVID-19, this lack of granularity in stratification may results in a loss of sensitivity in identifying differences on some indicators. Secondly, OxCGRT includes data at countrylevel and, thus, the state-wide distribution was not analyzed. An analysis carried out within the national context may highlight particular local demographic, cultural, and socio-economical contexts able to affect policy intervention. Even taking these weaknesses into account, this database allows for systematic comparisons across countries. Finally, a further limit may be linked to the few number of states analyzed. However, these were chosen because they represent a broad range of public actions taken in response to pandemic in Europe.

In conclusion, although some studies $(9,17)$ show that some interventions such as closing school and restricting gathering places are effective to contain cases of COVID 19, the study' results demonstrate that specific interventions do not correlate with incident cases of COVID-19 in the four considered European countries. This raises the question of why similar policy measures appeared effective in stemming the outbreak in other countries, as China (11), and have had such a different impact across some European countries. Supported by the evidence in the scientific literature, this study suggested some hypotheses to answer the question that have implications for policy makers.

In the absence of perfect enforcement capacity by states, effectiveness of interventions can be influenced by local context and, especially, by socio-economic and demographic characteristics. On the other hand, the impact of interventions can be affected by cultural attitudes and behavioral norms. 
This conclusion implies that policy makers must analyze more carefully the context in which the policies are set and consider that, in those countries where a level of enforcement similar to China may not be feasible, people must voluntarily comply with restrictions to be effective $(25,26)$.

The second implication, consistent with the literature $(27,28)$, regards the importance of taking care of communication so that people have a correct perception either of the risk of the pandemic or the benefits of restrictions. This is all the more so when it comes to individual mobility decisions, which entail a delicate trade-off between the chance of contracting (or diffusing) a disease and the costs associated with significant alterations of daily activities and that depends on the amount, quality, and interpretation of information available. The literature (29-31) highlighted that satisfaction with information received from the local government during an emergency seems to be related to the higher ability of an individual, group, or organization to continue its existence in the face of disaster such as pandemic.

\section{REFERENCES}

1. Cucinotta D, Vanelli M. WHO declares COVID-19 a pandemic. Acta Biomed. (2020) 91:157-60. doi: 10.23750/abm.v91i1.9397

2. Hammoumi A, Qesmi R. Impact assessment of containment measure against COVID-19 spread in Morocco. Chaos Solitons Fractals. (2020) 140:110231. doi: 10.1016/j.chaos.2020.110231

3. Wilder-Smith A, Freedman DO. Isolation, quarantine, social distancing and community containment: pivotal role for old-style public health measures in the novel coronavirus (2019-nCoV) outbreak. J Travel Med. (2020) 27:taaa020. doi: 10.1093/jtm/taaa020

4. Cross M, Ng S-K, Scuffham P. Trading health for wealth: the effect of COVID-19 response stringency. Int J Environ Res Public Health. (2020) 17:8725. doi: 10.3390/ijerph17238725

5. Meunier T. Full Lockdown Policies in Western Europe Countries Have No Evident Impacts on the COVID-19 Epidemic. medRxiv [Internet] (2020). Available online at: http://medrxiv.org/content/early/2020/05/01/2020.04.24. 20078717.abstract (accessed February 12, 2021).

6. Hale T, Webster S, Petherick A, Phillips T, Kira B. Oxford COVID-19 Government Response Tracker, Blavatnik School of Government [Internet] (2021). Available online at: https://covidtracker.bsg.ox.ac.uk (Accessed February 16, 2021]

7. Soucy J-PR, Sturrock SL, Berry I, Westwood DJ, Daneman N, MacFadden DR, et al. Estimating Effects of Physical Distancing on the COVID-19 Pandemic Using an Urban Mobility Index. medRxiv [Internet] (2020). Available online at: http://medrxiv.org/content/early/2020/05/24/2020.04.05.20054288. abstract (accessed February 12, 2021).

8. Chinazzi M, Davis JT, Ajelli M, Gioannini C, Litvinova M, Merler S, et al. The effect of travel restrictions on the spread of the 2019 novel coronavirus (COVID-19) outbreak. Science. (2020) 368:395-400. doi: 10.1126/science.ab a9757

9. Brauner JM, Mindermann S, Sharma M, Johnston D, Salvatier J, Gavenčiak $\mathrm{T}$, et al. Inferring the effectiveness of government interventions against COVID-19. Science. (2021) 371:eabd9338. doi: 10.1126/science.ab d9338

10. Dehning J, Zierenberg J, Spitzner FP, Wibral M, Neto JP, Wilczek M, et al. Inferring change points in the spread of COVID-19 reveals the effectiveness of interventions. Science. (2020) 369:eabb9789. doi: 10.1126/science.abb9789

11. Kraemer MUG, Yang C-H, Gutierrez B, Wu C-H, Klein B, Pigott DM, et al. The effect of human mobility and control measures on the COVID19 epidemic in China. Science. (2020) 368:493-7. doi: 10.1126/science.abb4 218

12. Blavatnik School of Government and University of Oxford. Relationship Between Number of COVID-19 Cases and Government Response [Internet]
Identifying the determinants of the effectiveness of adopted measures was not the aim of this study, thus, further research is needed on factors that influence the effects of control measures and public health policies to corroborate our implications.

\section{DATA AVAILABILITY STATEMENT}

Publicly available datasets were analyzed in this study. This data can be found here: https://covidtracker.bsg.ox.ac.uk/about-api.

\section{AUTHOR CONTRIBUTIONS}

MG and GD: conceptualization, validation, and supervision. MN and SR: data curation. GP: formal analysis. MN, MG, and GD: methodology. MG: writing-original draft. MN, MG, and GD: writing-review and editing. All authors contributed to the article and approved the submitted version.

(2021). Available from: https://covidtracker.bsg.ox.ac.uk/stringency-map (Accessed January 15, 2021)

13. R Core Team. R: A Language and Environment for Statistical Computing [Internet] (2020). Available online at: https://www.r-project.org/ (accessed March 1, 2021).

14. Pfaff B. VAR, SVAR and SVEC models: implementation within R package vars. J Stat Softw.(2008) 27, 1-32. doi: 10.18637/jss.v027.i04

15. Tobías A. Evaluation of the lockdowns for the SARS-CoV-2 epidemic in Italy and Spain after one month follow up. Sci Total Environ. (2020) 725:138539. doi: 10.1016/j.scitotenv.2020.138539

16. Haug N, Geyrhofer L, Londei A, Dervic E, Desvars-Larrive A, Loreto V, et al. Ranking the effectiveness of worldwide COVID-19 government interventions. Nat Hum Behav. (2020) 4:1303-12. doi: 10.1038/s41562-020-01009-0

17. Barari S, Caria S, Davola A, Falco P, Fetzer T, Fiorin S, et al. Evaluating COVID-19 Public Health Messaging in Italy: Self-Reported Compliance and Growing Mental Health Concerns. medRxiv [Internet] (2020). Available online at: http://medrxiv.org/content/early/2020/04/05/2020.03.27.20042820. abstract (accessed March 1, 2021).

18. Cohen AK, Hoyt LT, Dull B. A descriptive study of COVID-19-related experiences and perspectives of a national sample of college students in spring 2020. J Adolesc Heal. (2020) 67:369-75. doi: 10.1016/j.jadohealth.2020.06.009

19. Park CL, Russell BS, Fendrich M, Finkelstein-Fox L, Hutchison M, Becker J. Americans' COVID-19 stress, coping, and adherence to CDC guidelines. J Gen Intern Med. (2020) 35:2296-303. doi: 10.1007/s11606-020-05898-9

20. Nivette A, Ribeaud D, Murray A, Steinhoff A, Bechtiger L, Hepp U, et al. Noncompliance with COVID-19-related public health measures among young adults in Switzerland: insights from a longitudinal cohort study. Soc Sci Med. (2021) 268:113370. doi: 10.1016/j.socscimed.2020.113370

21. Wright L, Fancourt D. Do predictors of adherence to pandemic guidelines change over time? A panel study of 21,000 UK adults during the COVID-19 pandemic. medRxiv [Preprint]. (2020) 1-31. doi: 10.1101/2020.11.10.20228403

22. Williams SN, Armitage CJ, Tampe T, Dienes K. Public perceptions and experiences of social distancing and social isolation during the COVID-19 pandemic: a UK-based focus group study. BMJ Open. (2020) 10:e039334. doi: 10.1136/bmjopen-2020-039334

23. Martin LR, Williams SL, Haskard KB, Dimatteo MR. The challenge of patient adherence. Ther Clin Risk Manag. (2005) 1:189-99.

24. Farina M, Lavazza A. Lessons from italy's and sweden's policies in fighting COVID-19: the contribution of biomedical and social competences. Front Public Heal. (2020)8:563397. doi: 10.3389/fpubh.2020. 563397

25. Tizzoni M, Bajardi P, Decuyper A, Kon Kam King G, Schneider CM, Blondel $\mathrm{V}$, et al. On the use of human mobility proxies for modeling epidemics. 
PLoS Comput Biol. (2014). 10:e1003716. doi: 10.1371/journal.pcbi.1 003716

26. Reluga TC. Game theory of social distancing in response to an epidemic. PLoS Comput Biol. (2010) 6:1000793. doi: 10.1371/journal.pcbi.10 00793

27. Charoenwong B, Kwan A, Pursiainen V. Social connections with COVID-19affected areas increase compliance with mobility restrictions. Sci Adv. (2020) 6:eabc3054. doi: 10.1126/sciadv.abc3054

28. Houston JB. Community resilience and communication: dynamic interconnections between and among individuals, families, and organizations. J Appl Commun Res. (2018) 46:19-22. doi: 10.1080/00909882.2018.14 26704

29. Cohen O, Goldberg A, Lahad M, Aharonson-Daniel L. Building resilience: the relationship between information provided by municipal authorities during emergency situations and community resilience. Technol Forecast Soc Change. (2017) 121:119-25. doi: 10.1016/j.techfore.2016. 11.008

30. Norris FH, Stevens SP, Pfefferbaum B, Wyche KF, Pfefferbaum RL. Community resilience as a metaphor, theory, set of capacities, and strategy for disaster readiness. Am J Community Psychol. (2008) 41:127-50. doi: 10.1007/s10464-0079156-6
31. Longstaff PH, Yang S-U. Communication management and trust: their role in building resilience to "surprises" such as natural disasters, pandemic flu, and terrorism. Ecol Soc. (2008) 13:art3. doi: 10.5751/ES-02232-130103

Conflict of Interest: The authors declare that the research was conducted in the absence of any commercial or financial relationships that could be construed as a potential conflict of interest.

Publisher's Note: All claims expressed in this article are solely those of the authors and do not necessarily represent those of their affiliated organizations, or those of the publisher, the editors and the reviewers. Any product that may be evaluated in this article, or claim that may be made by its manufacturer, is not guaranteed or endorsed by the publisher.

Copyright (c) 2021 Gianino, Nurchis, Politano, Rousset and Damiani. This is an open-access article distributed under the terms of the Creative Commons Attribution License (CC BY). The use, distribution or reproduction in other forums is permitted, provided the original author(s) and the copyright owner(s) are credited and that the original publication in this journal is cited, in accordance with accepted academic practice. No use, distribution or reproduction is permitted which does not comply with these terms. 